\title{
EFFECTS OF PRECIPITATION ON SERRATED YIELDING IN INCONEL 718
}

\author{
M.L. Weaver and C.S. Hale \\ Department of Metallurgical \& Materials Engineering \\ The University of Alabama \\ Box 870202 \\ Tuscaloosa, Alabama 35487-0202
}

\begin{abstract}
The influence of precipitate distribution on the occurrence of dynamic strain aging has been investigated in Inconel 718. In process annealed and solution treated materials, serrated yielding has been observed in the temperature range $400 \mathrm{~K}-900 \mathrm{~K}$. Three different types of serrations, identified as A, B and C serrations were observed depending upon the temperature, strain rate, and test mode (i.e., tension or compression). Types $\mathrm{A}$ and $\mathrm{B}$ serrations were observed in the lower temperature range of $400 \mathrm{~K}-\sim 750 \mathrm{~K}$ while type $\mathrm{C}$ serrations were observed in the temperature range $\sim 750 \mathrm{~K}-900 \mathrm{~K}$. An average activation energy, calculated using five different analysis techniques, of $117 \pm 29 \mathrm{~kJ} / \mathrm{mol}$ was determined for types A and B serrated flow while the average activation energy ranged from $185 \pm 42 \mathrm{~kJ} / \mathrm{mol}$ to $206 \pm 39$ $\mathrm{kJ} / \mathrm{mol}$ for type $\mathrm{C}$ serrated flow. Annealing the solution treated materials at $1033 \mathrm{~K} / 8$ hours resulted in a contraction of the regime associated with serrated flow and in a change in serration type from types $\mathrm{A}$ and $\mathrm{B}$ to type $\mathrm{C}$. Continued annealing for 110 hours results in a complete disappearance of serrated yielding. Comparison of the results with literature data suggest that the rate controlling mechanisms for dynamic strain aging are the migration of interstitial solutes for type A and B serrations and the migration of substitutional solutes for type $\mathrm{C}$ serrations. The disappearance of serrated flow at longer aging times is attributed to solute depletion due to precipitation.
\end{abstract}

Superalloys 718.625.706 and Various Derivatives

Edited by E.A. Loria

TMS (The Minerals. Metals \& Materials Society), 2001 


\section{Introduction}

Strain aging is a time dependent strengthening or hardening caused by interactions between diffusion solute atoms and mobile dislocations. This phenomenon is possible in all crystalline materials where deformation occurs by dislocation motion. Thus it is not surprising that manifestations associated with strain aging have been reported in a number of Ni-based superalloys [1-13]. The most common manifestations of strain aging include: yield stress plateaus, reduced tensile elongation, sharp upper yield points, flow stress transients upon an upward change in strain rate, negative strain rate sensitivity and serrated stress-strain curves, also known as the Portevin-LeChatelier (PLC) effect. With reference to the PLC effect, several researchers have shown that the range of temperatures and strain rates where the PLC effect occurs can be altered by precipitation $[1,2,4,7-9,11,13-16]$. However, no general consensus exists concerning the how precipitation actually alters the kinetics of the PLC effect and of strain aging in general. The purpose of this paper is to assess the influence of precipitation on the underlying mechanisms causing serrated flow in a conventional precipitation strengthened Ni-based superalloy. The results are discussed with respect to prior experimental observations and classical mechanisms for strain aging.

\section{Experimental Procedure}

Two sheets of Inconel 718, one of superplastic forming grade and one of conventional grade, were obtained from Special Metals Incorporated (Huntington, WV). Both sheets received a continuous process anneal at Special Metals $(1200 \mathrm{~K}$ at $274 \mathrm{~m} / \mathrm{s})$. Some specimens were heattreated using a two-step procedure: solution treat at $1311 \mathrm{~K}, 1 \mathrm{~h}$, water quench (WQ) $+1033 \mathrm{~K}$, $8 \mathrm{~h}$ or $110 \mathrm{~h}, \mathrm{WQ}$. For the remainder of this document the $8 \mathrm{~h}$ aging treatment will be referred to as underaged while the $110 \mathrm{~h}$ treatment will be referred to as overaged. The chemical compositions of the two sheets are provided in Table I. Dogbone tensile specimens and rectangular compression specimens were machined from the sheet such that the test axes were parallel to the rolling directions. Tensile and compression tests were preformed over a range of strain rates and test temperatures on an Instron 5581 electromechanical load frame. Samples for scanning electron microscopy (SEM) were prepared using the three-step preparation procedures outlined by Radavich [17]. Samples for transmission electron microscopy (TEM) were twin jet electropolished in a solution consisting of seven parts methanol and one part sulfuric acid at $258 \mathrm{~K}, 12 \mathrm{~V}$ and $60 \mathrm{~mA}$. TEM examinations were conducted in a Hitachi H8000 microscope operated at an accelerating voltage of $200 \mathrm{kV}$.

Table I: Chemical Composition of As Received Materials (wt.\%)

\begin{tabular}{|c|c|c|c|c|c|c|c|}
\hline \multicolumn{8}{|c|}{ Conventional } \\
\hline $\mathrm{C}$ & $\mathrm{Mn}$ & $\mathrm{Fe}$ & $\mathrm{S}$ & $\mathrm{Si}$ & $\mathrm{Cu}$ & $\mathrm{Ni}$ & $\mathrm{Cr}$ \\
\hline 0.03 & 0.13 & 17.78 & 0.0006 & 0.070 & 0.03 & 53.76 & 18.39 \\
\hline $\mathrm{Al}$ & $\mathrm{Ti}$ & $\mathrm{Co}$ & $\mathrm{Mo}$ & $\mathrm{Nb}$ & $\mathrm{Ta}$ & $\mathrm{P}$ & $\mathrm{B}$ \\
\hline 0.46 & 1.09 & 0.06 & 3.07 & 5.11 & 0.01 & 0.008 & 0.003 \\
\hline \multicolumn{7}{|c|}{ Superplastic Forming Grade } \\
\hline $\mathrm{C}$ & $\mathrm{Mn}$ & $\mathrm{Fe}$ & $\mathrm{S}$ & $\mathrm{Si}$ & $\mathrm{Cu}$ & $\mathrm{Ni}$ & $\mathrm{Cr}$ \\
\hline 0.03 & 0.08 & 17.90 & 0.001 & 0.110 & 0.09 & 53.85 & 18.26 \\
\hline $\mathrm{Al}$ & $\mathrm{Ti}$ & $\mathrm{Co}$ & $\mathrm{Mo}$ & $\mathrm{Nb}$ & $\mathrm{Ta}$ & $\mathrm{P}$ & $\mathrm{B}$ \\
\hline 0.53 & 1.06 & 0.15 & 3.01 & 4.91 & 0.01 & 0.011 & 0.002 \\
\hline
\end{tabular}




\section{Results}

Figure 1 shows representative scanning electron microscopy (SEM) micrographs for the process annealed and aged materials used in this study. The process annealed Inconel 718 sheets (Figure $1 \mathrm{a}$ and $\mathrm{b}$ ) consisted of $\gamma$-Ni solid solution matrices and sparse distributions of primary carbide particles $(10 \mu \mathrm{m})$ and sub-micron sized $\delta-\mathrm{Ni}_{3}(\mathrm{Nb}, \mathrm{Fe})$ precipitates located both at grain boundaries and within the grain interiors. In contrast, underaged material (Figure 1c) contained high densities of intragranular lenticular precipitates and coarse grain boundary precipitates in addition to the aforementioned primary carbides. The intragranular precipitates were too small to characterize using energy dispersive spectroscopy (EDS) in the SEM, however, based upon the extensive Atom Probe Field Ion Microscopy (APFIM) investigations of Burke and Miller [18-20], the intragranular precipitates are believed to be $\gamma^{\prime \prime}$ while the coarse grain boundary precipitates are believed to be either $\delta$ or Laves phases.
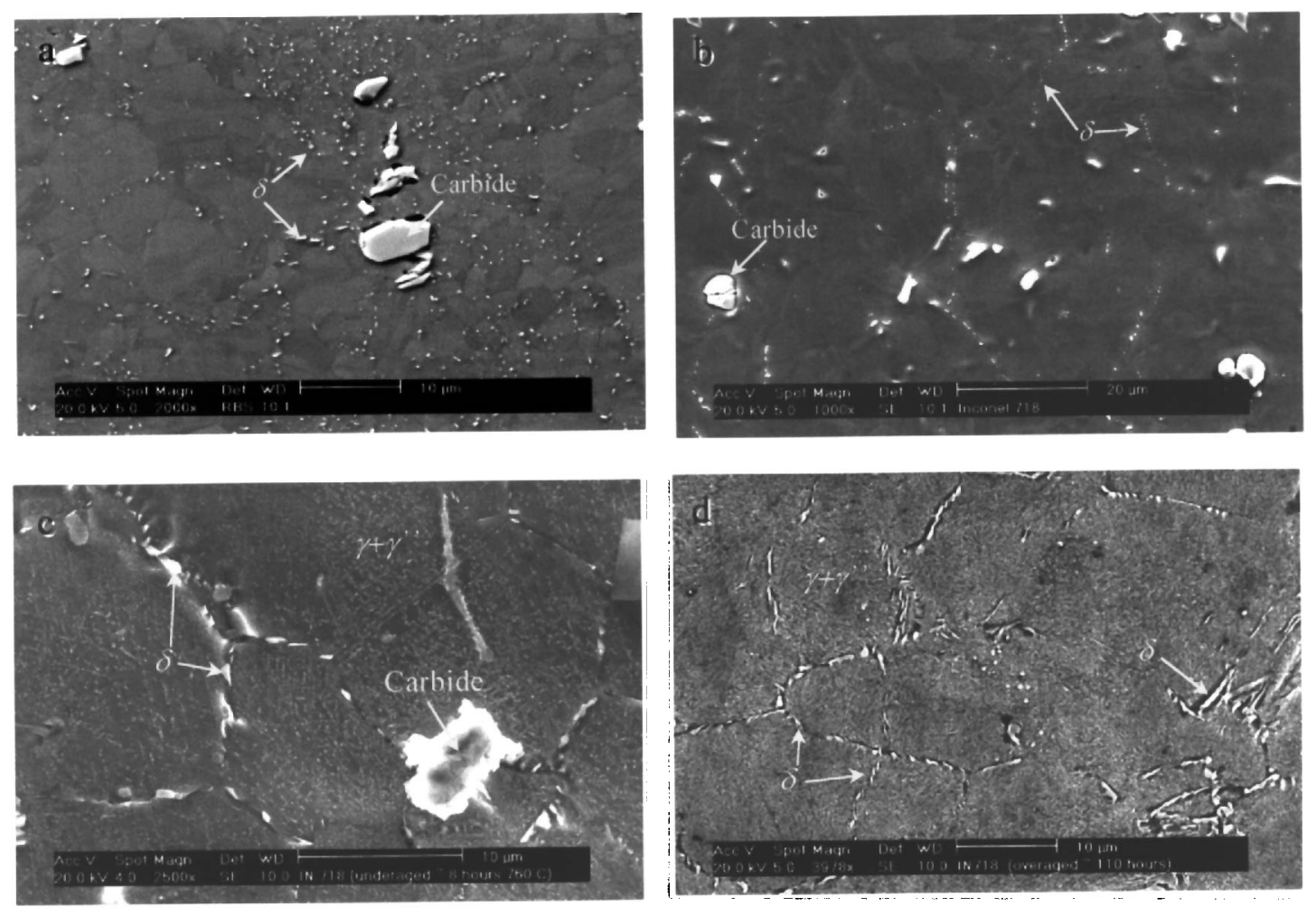

Figure 1. Representative SEM micrographs of Inconel 718. (a,b) Process annealed; (c) underaged; and (d) overaged

Overaging (Figure 1d) induced significant coarsening of the intragranular and grain boundary precipitates. The size of the grain boundary precipitates in the overaged material made them amenable for compositional analysis using EDS. In the regions selected for evaluation, the average measured composition for the grain boundary phase was 6.2 at. $\% \mathrm{Nb}, 1.4 \% \mathrm{Al}, 1.5 \%$ $\mathrm{Ti}, 12 \% \mathrm{Mo}, 15 \% \mathrm{Fe}, 23 \% \mathrm{Cr}$ and balance $\mathrm{Ni}$. This composition is in good agreement with the previously reported APFIM data of Burke and Miller [19] for similarly aged material of Alloy 718 , and is consistent with a $(\mathrm{Ni}, \mathrm{Fe}, \mathrm{Cr})_{2}(\mathrm{Nb}, \mathrm{Mo}, \mathrm{Si})$-type Laves phase. It is expected, however. that a significant fraction of the grain boundary precipitates will be equilibrium $\delta$.

Deformation at temperatures up to $900 \mathrm{~K}$ resulted in no significant microstructural changes for the range of test times and deformation temperatures used in this study. Even at the lowest 
strain rate, the longest test times were approximately 3600 s (i.e., 60 minutes). This is consistent with the prior investigations of Barker et al. [21] who in a study of the long-term stability of Inconel 718 reported that extended exposures at temperatures in excess of $810 \mathrm{~K}$ were necessary to produce significant microstructural changes.

The temperature and strain rate dependence of the 0.2 percent offset yield stress, $\sigma_{0.2}$, for process annealed and underaged Inconel 718 is summarized in Figure 2. Broad yield stress plateaus were observed on the $\sigma_{0.2}$ versus temperature plots in the range $\sim 500-900 \mathrm{~K}$. In this regime, $\sigma_{0.2}$ was relatively insensitive to changes in temperature. The yield stress was also observed to increase as strain rate decreased implying a negative strain rate sensitivity (SRS) in those temperature ranges (i.e., $\sim 500-700 \mathrm{~K}$ for process annealed and $\sim 700-900 \mathrm{~K}$ for underaged). These observations were later confirmed using strain rate change experiments. At temperatures in excess of $950 \mathrm{~K}$, the yield stress was observed to increase slightly. In limited tests of overaged material, $\sigma_{0.2}$ was observed to decrease with increasing $T$.

Segments of representative compressive stress-strain curves are presented in Figure 3 for process annealed and aged material. In the process annealed material deformed at a strain rate of $1.4 \times 10^{-3} \mathrm{~s}^{-1}$, for example, smooth stress-strain curves were observed at temperatures below $490 \mathrm{~K}$ and above $1089 \mathrm{~K}$. Consistent with the negative SRS values reported above, serrated stress strain curves were observed at intermediate temperatures for each strain rate. In the underaged material deformed at the same strain rates, serrated stress-strain curves were observed over a narrower range of temperatures (i.e., $\sim 628 \mathrm{~K}$ to $823 \mathrm{~K}$ ). In the overaged material, smooth stress-strain curves were observed throughout the entire ranges of testing. As has also been shown in other studies [5,22-28], the regime where the PLC effect occurred was shifted to higher temperatures than is typical for $\mathrm{Ni}$ (i.e., $\sim 223 \mathrm{~K}$ to $573 \mathrm{~K}$ ) [29]

The serrations were classified as types A, B and/or C according to the classification scheme of Rodriguez [30,31]. In the process annealed material, type $A$ and $B$ serrations were observed at lower temperatures (e.g., between $504 \mathrm{~K}$ and $738 \mathrm{~K}$ at $\dot{\varepsilon}=1.4 \times 10^{-3} \mathrm{~s}^{-1}$ ) while type C serrations were observed at higher temperatures (e.g., between $793 \mathrm{~K}$ and $1033 \mathrm{~K}$ at $\dot{\varepsilon}=1.4 \times$ $10^{-3} \mathrm{~s}^{-1}$ ). In the underaged material, only type $\mathrm{C}$ serrated flow was observed. No serrated flow was observed in the overaged material. In material exhibiting type $\mathrm{C}$ serrations, each load drop was accompanied by an audible click during testing.

Flow stress serrations were preceded by a critical onset strain $\varepsilon_{\mathrm{c}}$ where smooth stress-strain behavior was observed. The magnitude of $\varepsilon_{\mathrm{c}}$ was observed to vary with temperature and strain rate (Figure 4 ). In process annealed material, $\varepsilon_{\mathrm{c}}$ was observed to decrease with increasing $\dot{\varepsilon}$ and decreasing temperature (i.e., normal behavior) to a minimum followed by a further increase with increasing $\dot{\varepsilon}$ and decreasing temperature (i.e., inverse behavior). In underaged materials, only inverse behavior was observed. It was additionally observed that $\varepsilon_{\mathrm{c}}$ was larger in underaged material than in process annealed material. Interestingly, the apparent transition from types $\mathrm{A}$ and/or $\mathrm{B}$ to type $\mathrm{C}$ serrations was found to coincide with the aforementioned change in the temperature and strain rate dependence of $\varepsilon_{\mathrm{c}}$ from normal to inverse.

The kinetic aspects associated with serrated yielding were evaluated using the methods described in reference [32]. The resulting activation energies and strain aging parameters compiled in the present investigation are summarized in Table II along with results obtained in our prior investigation [32]. An average activation energy of $117 \pm 29$ was determined for the onset of types A and/or B serrated flow. The average activation energies for the onset of type C serrated flow ranged from $185 \pm 42$ to $206 \pm 39 \mathrm{~kJ} / \mathrm{mol}$. 


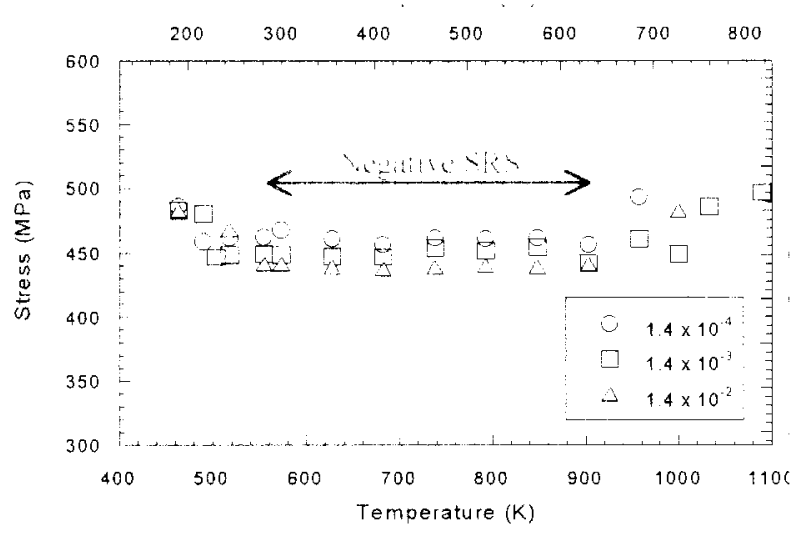

(a)

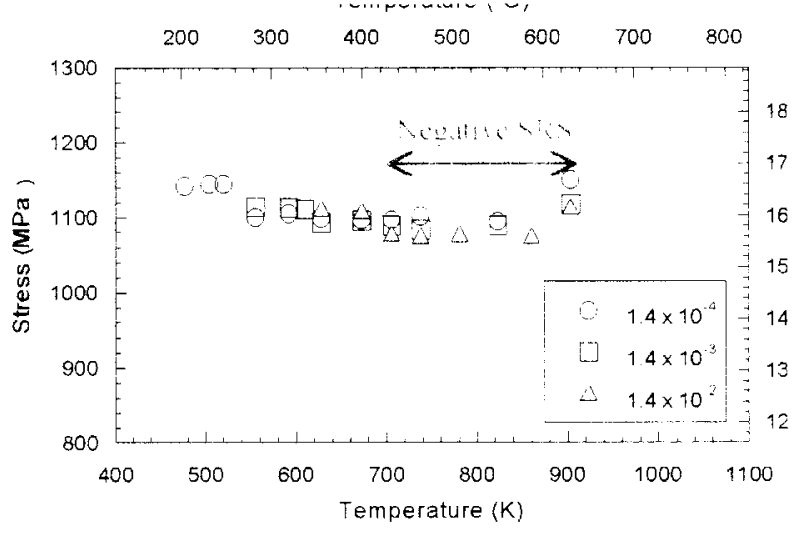

(b)

Figure 2. Temperature dependence of $0.2 \%$ offset yield stress (YS) for process annealed and underaged Inconel 718 tested at base strain rates of $1.4 \times 10^{-4}, 1.4 \times 10^{-3}$, and $1.4 \times 10^{-2} \mathrm{~s}^{-1}$. (a) Process annealed and (b) underaged.

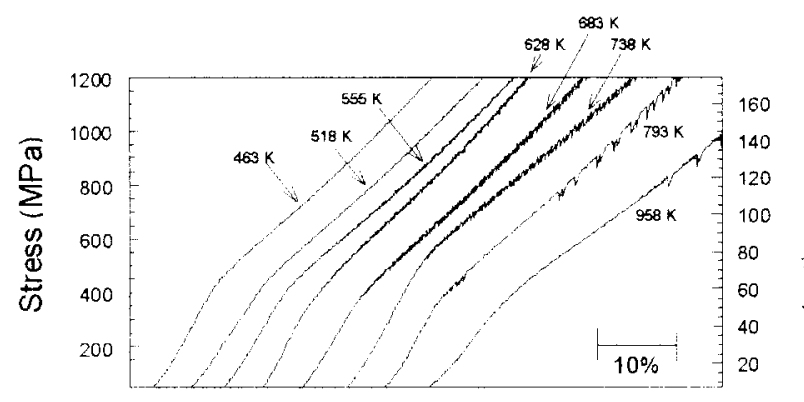

Figure 3. Representative compressive stress-strain curves for process annealed Inconel 718 tested in compression $\left(\dot{\varepsilon}=1.4 \times 10^{3} \mathrm{~s}^{-1}\right)$.

Percent Strain

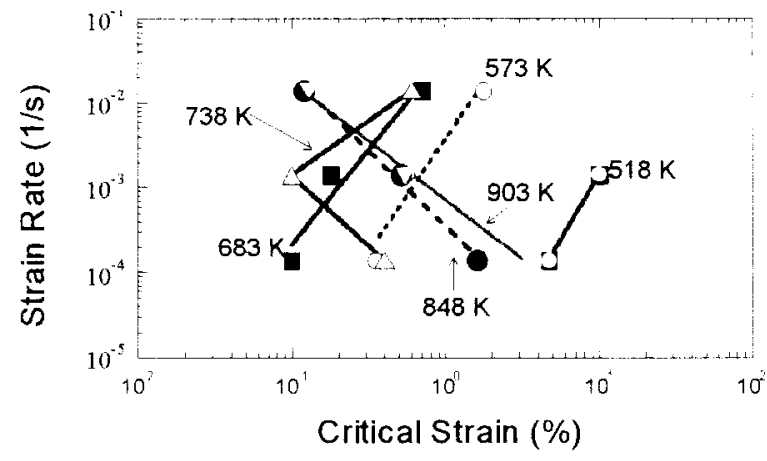

(a)

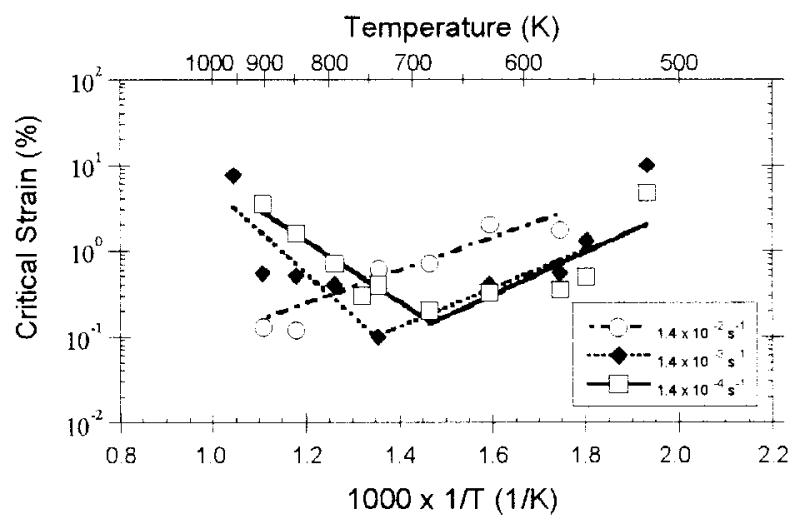

(b)

Figure 4. Representative plots of the temperature and strain rate dependence of $\varepsilon_{\mathrm{c}}$ for process annealed Inconel 718. (a) Strain rate dependence and (b) temperature dependence.

One important result obtained from the analysis methods used in this study was the value of the exponent $m+\beta$, which is related to the concentration of vacancies and the mobile dislocation density through the following equation $[33,34]$ :

$$
\varepsilon_{c}^{m \nmid \beta}=K \dot{\varepsilon} \exp (Q / R T)
$$


Table II: Summary of activation energy values for serrated flow in Inconel 718 compiled from the present investigation and reference [32].

\begin{tabular}{|c|c|c|c|c|}
\hline \multirow{2}{*}{ Analysis Method } & \multicolumn{3}{|c|}{ Activation Energy $\left(\mathrm{kJ} \mathrm{mol}^{-1}\right)$} \\
& \multicolumn{2}{|c|}{ Process Annealed } & \multicolumn{2}{c|}{ Underaged } \\
\cline { 2 - 5 } & Type A/B & Type C & Type A/B & Type C \\
\hline 1. Arrhenius Method. & $99-115$ & $206-272$ & -na- & 222 \\
\hline 2. In $\varepsilon_{c}$ vs. $1 / T$ & $77-100$ & $150-207$ & -na- & $109-238$ \\
\hline 3. Stress Drop Method & $71-114$ & -na- & -na- & $142-235$ \\
\hline 4. McCormick Method & $86-161$ & -na- & -na- & -na- \\
\hline 5. Intercept Method & $105-170$ & -na- & -na- & -na- \\
\hline Average & $117 \pm 29$ & $206 \pm 39$ & -na- & $185 \pm 42$ \\
\hline
\end{tabular}

-na- denotes insufficient data for calculation or no serrations observed

where $Q$ is the activation energy for the onset of serrated flow, $R$ is the gas constant, $T$ is the temperature and $K$ is a constant. The value of this exponent is often be used to identify the mechanism or mechanisms responsible for serrated yielding. It is generally accepted that when $m+\beta$ is in the range 0.5 to 1 , interstitial solutes are responsible for strain aging whereas when $m+\beta$ is in the range 2 to 3 , substitutional solutes are responsible. The values of $m+\beta$ for the process annealed material were found to lie in the range 0.9 to 3.0 in the regime where $\varepsilon_{\mathrm{c}}$ increased with increasing $\dot{\varepsilon}$ (i.e., normal behavior) and in the range -1.3 to -1.8 where $\varepsilon_{\mathrm{c}}$ decreased with increasing $\dot{\varepsilon}$ (i.e., inverse behavior). Though the average $m+\beta$ value of $2.2 \pm$ 1.0 in the normal range suggests a substitutional mechanism, the range of values suggests that neither interstitial nor substitutional solutes are solely responsible for the observed serrated yielding. No explanation exists for the occurrence of negative $m+\beta$ values in the inverse range.

\section{Discussion of Results}

The results of tension and compression tests performed on two grades of Inconel 718 over a range of temperatures and strain rates show that a strain aging mechanism operates at intermediate temperatures and that the kinetics of strain aging, in particular the occurrence of the PLC effect, are influenced by precipitation. In the present study, the PLC effect was observed in process annealed and underaged material, whereas, no PLC effect was observed in overaged material. In underaged material, serrated flow occurred at higher temperatures and at higher $\varepsilon_{\mathrm{c}}$ 's than in process annealed material. The regime of serrated flow was also narrower for the underaged material.

The reported activation energies for the diffusion of some common interstitial and substitutional solutes in $\mathrm{Ni}$ and Ni-base alloys are presented in Table III. In accord with references [35-37], the activation energies for dislocation pipe diffusion have been calculated as $Q_{\text {pipe }}=0.65 \times Q_{\text {lattice. }}$ The average activation energies for types $\mathrm{A}$ and/or $\mathrm{B}$ serrated flow, which were observed only in the process annealed material, are comparable to the reported activation energies for lattice and pipe diffusion of $\mathrm{C}$ in $\mathrm{Ni}$ and but are slightly higher than the previously reported activation energies for serrated flow in Ni-C alloys $[28,29,38]$. This indicates that type $\mathrm{A}$ and/or $\mathrm{B}$ serrated flow are most likely a product of interactions between mobile dislocations and interstitial solute atmospheres. The average activation energies for type $\mathrm{C}$ serrated flow, are much greater than the ones that would be expected for interstitial solutes are consistent with the reported activation energies for the diffusion of substitutional 
solutes in $\mathrm{Ni}$-base alloys indicating that type $\mathrm{C}$ serrated flow is most likely a product of interactions between mobile dislocations and substitutional solutes.

Table III: Diffusion data for various solutes in $\mathrm{Ni}$

\begin{tabular}{|c|c|c|c|}
\hline Solute & Type/Condition & $Q(\mathrm{~kJ} / \mathrm{mol})$ & Refs \\
\hline $\mathrm{C}$ in $\mathrm{Ni}$ & Lattice/Pipe & $139 / 90^{*}$ & {$[39]$} \\
\hline $\mathrm{C}$ in Ni-Fe-Cr Austenite & Lattice/Pipe & $161-183 / 105^{*}-119^{*}$ & {$[40]$} \\
\hline $\mathrm{Fe}$ in $\mathrm{Ni}$ & Lattice/Pipe & $253 / 165^{*}$ & {$[39]$} \\
\hline $\mathrm{Cr}$ in Inconel 600 & Lattice/Pipe & $\sim 280 / 182^{*}$ & {$[37]$} \\
\hline $\mathrm{Cr} \& \mathrm{Fe}$ in Ni-Fe-Cr Austenite & Lattice/Grain Boundary & $289-310 / 174^{\#}-219^{\#}$ & {$[41]$} \\
\hline $\mathrm{Ni}$ in Ni & Self/Pipe & $280 / 184^{\#}$ & {$[42,43]$} \\
\hline $\mathrm{Ni}$ in $\mathrm{Ni}-\mathrm{Cr}$ alloy & Lattice/Pipe & $285-295 / 185^{\#}-192^{\#}$ & {$[42-44]$} \\
\hline $\mathrm{Mo}$ in $\mathrm{Ni}$ & Lattice/Pipe & $213 / 139^{*}$ & {$[39]$} \\
\hline $\mathrm{Al}$ in $\mathrm{Ni}$ & Lattice/Pipe & $270 / 176^{*}$ & {$[45]$} \\
\hline $\mathrm{Ti}$ in $\mathrm{Ni}$ & Lattice/Pipe & $257 / 167^{*}$ & {$[45]$} \\
\hline $\mathrm{Nb}$ in $\mathrm{Ni}$ & Lattice/Pipe & $202 \pm 5 / 131^{*}$ & {$[46]$} \\
\hline
\end{tabular}

calculated as $0.65 \mathrm{D}_{\mathrm{L}}$; ${ }^{*}$ experimentally measured

As noted in the results section, the value of $m+\beta$ is often used to identify the mechanisms causing serrated yielding. In this study the average $m+\beta$ values were found to lie well beyond the range that characterizes serrated flow exclusively by interstitial solutes though the range of individual $m+\beta$ values and the calculated activation energies appear to indicate otherwise Chen and Chaturvedi [11] suggested that the value of $m+\beta$ might not be the best criterion for assigning the mechanism that causes serrated flow, in particular in the range where $\varepsilon_{\mathrm{c}}$ changes from normal to inverse. This is supported by reports of a broad transition from normal to inverse behavior $[29,47-50]$, which can make accurate determination of $m+\beta$ difficult.

Considering that the range of $m+\beta$ values stretches from $\sim 1$ to $\sim 3$, another possibility is that serrated yielding is caused by a combination of interstitial and substitutional solutes or by some entirely different mechanism. One potentially valid explanation is "interaction solid solution hardening" (ISSH) [51-53]. ISSH, as described by Baird and Jamieson [51], refers to an enhanced form of strengthening that arises from the simultaneous presence of substitutional and interstitial solute atoms that exhibit a high affinity for each other. The degree of strengthening is related to the magnitude of the interaction between interstitial and substitutional solutes and can be classified in two ways: (1) When interstitial solutes are more strongly attracted to dislocations, solid solution strengthening occurs but is extended to higher temperatures due to a reduction in the mobility of the dislocation atmospheres; (2) When interstitial solutes are more strongly attracted to substitutional solute atoms, solid solution strengthening due to interstitials will be extended to higher temperatures than in binary interstitial containing systems due to a reduction in the mobility of the interstitial atoms. In both cases, the reduced mobility of interstitial solute atoms due to their associations with substitutional solute atoms would cause the strain aging regime to shift or to extend to higher temperatures. Though this theory was devised for ferritic iron-base alloys, the extensively reported shifts of the strain aging regime in Ni-base alloys [5,22-28] to higher temperatures than is typical of $\mathrm{Ni}[29]$ and the well known fact that some substitutional solutes, namely $\mathrm{Nb}$, $\mathrm{Ti}$, and $\mathrm{Cr}$, exhibit relative strong affinities for carbon [54-56] supports the proposed occurrence of ISSH in Inconel 718. 
The change in serration type from $\mathrm{A}$ and/or $\mathrm{B}$ to $\mathrm{C}$ coupled with the dramatically different activation energies and $m+\beta$ values can also be explained, at least qualitatively, in terms of ISSH. Assuming that at lower temperatures carbon binds more strongly to dislocations, it is proposed that solute atmospheres would be dragged along with only a mild to moderate increase in activation energy above that typically observed in $\mathrm{Ni}$. As noted previously, the activation energies reported for low temperature (i.e., types $\mathrm{A}$ and $\mathrm{B}$ ) serrated flow are slightly higher than the values reported for binary $\mathrm{Ni}-\mathrm{C}$ alloys $(\sim 50-70 \mathrm{~kJ} / \mathrm{mol})$, which qualitatively lends credence to the proposed mechanism.

At higher temperatures, where substitutional solutes are more mobile, it is proposed that there will be a higher driving force for strong interstitials to interact with substitutional solutes, a fact that is supported by reports of grain boundary carbide precipitation [54-56]. The precipitation of grain boundary carbide precipitates, however, will be restricted by the depletion of substitutional solutes that will diffuse readily to form $\gamma^{\prime}$ and/or $\gamma^{\prime \prime}$ precipitates [57]. This will combine to make the diffusion of substitutional solutes the rate limiting factor controlling strain aging at elevated temperatures, which should cause the activation energy for serrated flow to increase to levels associated with the diffusion of substitutional solutes.

Serrated yielding was observed to disappear with aging. First, underaging induced a disappearance of types A and B serrated flow. Finally overaging induced a disappearance of all serrated flow. Assignment of a definitive mechanism for the disappearance of serrated flow in Inconel 718 is difficult. For types $\mathrm{A}$ and $\mathrm{B}$ serrated yielding, one could argue, assuming that interstitial carbon is the species responsible, that the disappearance of this type of serration is caused by a reduction in the carbon concentration in the matrix during aging due to carbide precipitation [54-56]. According to Radavich [58], however, the primary carbide in alloy 718 , $\mathrm{NbC}$, is generally considered to be stable and thus is not influenced by brief thermal cycles below $\sim 1323 \mathrm{~K}$. The disappearance of serrated yielding in all overaged material coupled with the observed microstructural coarsening suggests that the disappearance is the result of a precipitation-induced depletion of solute atoms. The disappearance can also be explained in terms of ISSH in that long-term aging should induce the formation of $\gamma^{\prime \prime}$ and carbide precipitates, which would simultaneously deplete the matrix of the solutes that are presumed responsible for strain aging

In recent years, Hayes and Hayes [1,2] and Chen and Chaturvedi [11] have developed models that describe the delayed onset to serrated yielding and the disappearance of serrated yielding in terms of a series of the depletion of solutes from dislocation cores via solute-precipitate interactions. Though the mechanistic details differ, both models generally report that serrated flow in Inconel 718 depends upon the segregation and depletion of interstitial solutes to and from dislocation cores, which becomes more difficult or even impossible in aged materials due to interactions between solute atmospheres and solute sinks or due to precipitation. Both models support the proposed notion that ISSH could cause yield the observed delays in serrated yielding. However, more investigation is required to definitively identify the operative mechanisms.

\section{Conclusions}

The results indicate that serrated yielding in Inconel 718 is the result of dynamic strain aging. Three different types of serrations were observed over the range of temperatures and strain rates used in this study. Types $\mathrm{A}$ and $\mathrm{B}$ serrations, which were only observed in process annealed material, occurred at lower temperatures (i.e., $400 \mathrm{~K}-700 \mathrm{~K}$ ) while type $\mathrm{C}$ serrations, 
which were observed in process annealed and underaged material occurred at higher temperatures (i.e., $750 \mathrm{~K}-900 \mathrm{~K}$ ). Based on analysis of the activation energies for the onset of serrated flow and the kinetics of strain aging, the rate controlling mechanisms are suggested to be the migration of interstitial-substitutional solute pairs or clusters via interaction solid solution hardening which is partially substantiated by the shift in the regime of serrated flow above the range normally associated with nickel. The disappearance of types $\mathrm{A}$ and $\mathrm{B}$ serrated flow in underaged material and the complete disappearance of all serrated flow in overaged material is most likely a result of the depletion of the interstitial and substitutional solutes that are being tied up in precipitates. The proposed occurrence of ISSH complements the theoretical models proposed by Hayes and Hayes [1,2], and Chen and Chaturvedi [11] that explain the occurrence a delayed PLC effect in strain aging alloys.

\section{References}

1. R. W. Hayes and W. C. Hayes; "On the Mechanism of Delayed Discontinuous Plastic Flow in An Age-Hardened Nickel Alloy;" Acta Metallurgica, 30 (1982), 1295-1301.

2. R. W. Hayes; "On a Proposed Theory for the Disappearance of Serrated Flow in F.C.C. Ni Alloys;" Acta Metallurgica, 31 (1983), 365-371.

3. K. B. S. Rao, et al:; "Serrated Flow and Deformation Substructure at Room Temperature in Inconel 718 Superalloy During Strain Controlled Fatigue;" Scripta Metallurgica et Materialia, 32 (1995), 493-498.

4. E. S. Huron, Serrated Yielding in a Nickel-Base Superalloy (Warrendale, PA. The Minerals, Metals \& Materials Society, 1992), pp. 675-684.

5. S. H. Hong, et al; "Dynamic Strain Aging Behavior of Inconel 600 Alloy;" Superalloys 1996; edited by R. D. Kissinger, et al. (Warrendale, PA: The Minerals, Metals \& Materials Society, 1996), pp. 401-407.

6. C. P. Blankenship and M. F. Henry; "Observations of " $1000^{\circ} \mathrm{F}$ Embrittlement" in NiBase Superalloys;" Scripta Materialia, 34 (1996), 1461-1466.

7. L. M. Camus and G. Engberg; "Elevated Temperature Deformation of Cast Inconel 718;" High Temperature Materials and Processes, 9 (1990), 27-38.

8. H. Dybiec; "Aging Yield Point Effect in Inconel 718;" Archives of Metallurgy, 38 (1993), 449-457.

9. H. Dybiec and M. C. Chaturvedi; "Serrated Yielding in Inconel 718;" Archives of Metallurgy, 36 (1991), 341-352.

10. K. B. S. Rao, et al.; "Strain Rate and Temperature Dependence of Deformation and Fracture Behavior of a Nimonic PE 16 Superalloy;" High Temperature Materials and Processes, 7 (1986), 63-81.

11. W. Chen and M. C. Chaturvedi; "On the Mechanism of Serrated Deformation in Aged Inconel 718;" Materials Science and Engineering, A229 (1997), 163-168.

12. A. Sengupta and S. K. Putatunda; "Dynamic Strain Aging in a New Single Crystal Nickel-Based Superalloy (CMSX-4);" Journal of Testing and Evaluation, 23 (1995), 8794. 
13. G. Carotenuto, et al., The "Serrated Flow" in a Nickel-Base Superalloy (Milan, Italy: Engineering Materials Advisory Services, 1995), pp. 89-101.

14. H. X. Li and J. K. Park; "The serrated flow behavior of a binary Al-Li alloy tempered to conditions with and without $\delta$ ' precipitates;" Materials Science and Engineering, A280 (2000), 156-160.

15. E. Pink, S. Kumar and B. Tian; "Serrated flow of aluminum alloys influenced by precipitates;" Materials Science and Engineering, A280 (2000), 17-24

16. S. Dymek, et al.; "Effects of Long Range Ordering, Temperature and Strain Rate on Deformation Behavior of Ni-Mo-Cr Alloy;" Superalloys 1992; edited by S. D. Antolovich, et al. (Warrendale, PA: The Minerals, Metals \& Materials Society, 1992), pp. 685-694.

17. J. F. Radavich, Electron Metallography of Alloy 718 (Warrendale, PA: The Minerals, Metals and Materials Society, 1997), pp. 17-26.

18. M. K. Miller and M. G. Burke; "APFIM/TEM Characterization of Precipitation in Alloy 718;" Journal de Physique, 50-C8 (1989), 395-400.

19. M. G. Burke and M. K. Miller; "Precipitation in Alloy 718: A Combined AEM and APFIM Investigation;" Superalloys 718,625 and Various Derivatives; edited by E. A. Loria (Warrendale, PA: The Minerals, Metals \& Materials Society, 1991),

20. M. G. Burke and M. K. Miller; "Grain Boundary Intermetallic Phases in Alloy 718;" Alloy Phase Stability and Design; edited by G. M. Stocks, D. P. Pope and A. F. Giamei (Pittsburgh, PA: Materials Research Society, 1991), vol. 186, pp. 215-218.

21. J. F. Barker, E. W. Ross and J. F. Radavich; "Long time stability of Inconel 718;" Journal of Metals, 22 (1970), 31-41.

22. D. E. Sonon and G. V. Smith; "Effect of Grain Size and Temperature on the Strengthening of Nickel and a Nickel-Cobalt Alloy by Carbon;" Transactions of the Metallurgical Society of AIME, 242 (1968), 1527-1533.

23. J. S. Blakemore and E. O. Hall; "The Portevin-Le Chatelier Effect in Nickel-Copper Alloys;" Transactions of the Metallurgical Society of AIME, 242 (1968), 333-335.

24. J. S. Blakemore; "The Portevin-Le Chatelier Effect in Carburized Nickel Alloys;" Metallurgical Transactions, 1 (1970), 1281-1285.

25. J. S. Blakemore; "The Portevin-Le Chatelier Effect in Hydrogenated Nickel Alloys;" Metallurgical Transactions, 1 (1970), 151-156.

26. J. S. Blakemore; "The Portevin-Le Chatelier Effect in Hydrogenated Nickel;" Metallurgical Transactions, 1 (1970), 145-150.

27. M. K. Matta, B. D. Sharma and P. Dasgupta; "Serrated Yielding in Nickel-1.0 wt pct Titanium Alloy;" Metallurgical Transactions, 8A (1977), 220-221.

28. U. F. Kocks, R. E. Cook and R. A. Mulford; "Strain Aging and Strain Hardening in NiC Alloys;" Acta Metallurgica, 33 (1985), 623-638. 
29. Y. Nakada and A. S. Keh; "Serrated Flow in Ni-C Alloys;" Acta Metallurgica, 18 (1970), 437-443.

30. P. Rodriguez and S. Venkadesan; "Serrated Plastic Flow Revisited;" Key Engineering Materials, 103 (1995), 257-266.

31. P. Rodriquez; "Serrated Plastic Flow;" Bulletin of Materials Science, India, 6 (1984), 653-663.

32. C. L. Hale, W. S. Rollings and M. L. Weaver; "Activation Energy Calculations for Discontinuous Yielding In Inconel 718SPF;" Materials Science and Engineering A, A300 (2000), 153-164.

33. R. K. Ham and G. Jaffrey; "Dislocation Multiplication, Vacancy Accumulation, and the Onset of Jerky Flow During Forward and Reversed Strain in $\mathrm{Cu}-3.2$ at.\% $\mathrm{Sn}$;" Philosophical Magazine, 15 (1967), 247-256.

34. P. G. McCormick; "A Model for the Portevin-Le Chatelier Effect In Substitutional Alloys;" Acta Metallurgica, 20 (1972), 351-354.

35. P. G. Shewmon, Transformations in Metals (New York: McGraw-Hill, 1969).

36. J. W. Christian, The Theory of Transformations in Metals and Alloys (Oxford: Pergamon Press, 1975).

37. D. D. Pruthi, M. S. Anand and R. P. Agarwala; "Diffusion of Chromium in Inconel600;" Journal of Nuclear Materials, 64 (1977), 206-210.

38. A. M. Weinstein, P. Ferraglio and K. Mukherjee; "Dynamic Strain Aging of Carbon Doped Ni;" Materials Science and Engineering, 8 (1971), 198-202.

39. C. J. Smithels, Metals Reference Book (New York: Plenum Press, 1983).

40. J. Cermak and H. Mehrer; "Tracer Diffusion of ${ }^{14} \mathrm{C}$ in Austenitic Ni-Fe-Cr Alloys;" Acta Metallurgica et Materialia, 42 (1994), 1345-1350.

41. J. Cermak; "Grain Boundary Self-Diffusion of ${ }^{51} \mathrm{Cr}$ and ${ }^{59} \mathrm{Fe}$ in Austenitic Ni-Fe-Cr Alloys;" Materials Science and Engineering, A148 (1991), 279-287.

42. J. Cermak and Z. Cochnar; "Self-Diffusion of ${ }^{63} \mathrm{Ni}$ Along Dislocations;" Materials Science and Engineering, A174 (1994), 9-13.

43. A. M. Brown and M. F. Ashby; "Correlations for Diffusion Constants;" Acta Metallurgica, 28 (1980), 1085-1101.

44. J. Cermak and J. Ruzickova; "Grain Boundary Self-Diffusion of ${ }^{63} \mathrm{Ni}$ in Austenitic NiCr Alloys;" Materials Science and Engineering, A172 (1993), 153-157.

45. R. A. Swalin and A. Martin; "Solute Diffusion in Nickel-Base Substitutional Solid Solutions;" Transactions of the Metallurgical Society AIME, 206 (1956), 567-572.

46. R. V. Patil and G. B. Kale; "Chemical Diffusion of Niobium in Nickel;" Journal of Nuclear Materials, 230 (1996), 57-60. 
47. R. R. Jensen and J. K. Tien; "Temperature and Strain Rate Dependence of Stress-Strain Behavior in a Nickel-Base Superalloy;" Metallurgical Transactions, 16A (1985), 10491068 .

48. E. Pink; "The Effect of Precipitates on Characteristics of Serrated Flow in AlZn5Mg1;" Acta Metallurgica, 37 (1989), 1773-1781

49. D. Thevenet, M. Mliha-Touati and A. Zeghloul; "The Effect of Precipitation on the Portevin-Le Chatelier Effect in an Al-Zn-Mg-Cu Alloy;" Materials Science and Engineering, A266 (1999), 175-182.

50. J. Balik, P. Lukác and L. P. Kubin; "Inverse Critical Strains for Jerky Flow in Al-Mg Alloys;" Scripta Materialia, 42 (2000), 465-471.

51. J. D. Baird and A. Jamieson; "High-Temperature Tensile Properties of Some Synthesized Iron Alloys Containing Molybdenum and Chromium;" Journal of the Iron and Steel Institute, 210 (1972), 841-846.

52. R. L. Klueh and R. E. Oakes Jr.; "High Strain Rate Tensile Properties of Annealed 21/4 Cr-1 Mo Steel;" Journal of Engineering Materials and Technology, 98 (1976), 361-368.

53. R. L. Klueh; "Heat Treatment Effects on the Tensile Properties of Annealed $2.25 \mathrm{Cr}-$ 1Mo Steel;" Journal of Nuclear Materials, 68 (1977), 294-307.

54. I. Kirman and D. H. Warrington; "The Precipitation of $\mathrm{Ni}_{3} \mathrm{Nb}$ Phases in a Ni-Fe-Cr- $\mathrm{Nb}$ Alloy;" Metallurgical Transactions, 1 (1970), 2667-2675

55. M. Gao and R. P. Wei; "Grain Boundary Niobium Carbides in Inconel 718;" Scripta Materialia, 37 (1997), 1843-1849.

56. M. Sundararaman, P. Mukhopadhyay and S. Banerjee; "Carbide Precipitation in Nickel Base Superalloys 718 and 625 and their Effect on Mechanical Properties;" Superalloys 718 , 625, 706 and Various Derivatives; edited by E. A. Loria (Warrendale, PA: The Minerals, Metals and Materials Society, 1997), pp. 367-378.

57. K. Nakai, et al.; "Effects of Lattice Defect Behaviors on Pre-precipitation Stages of $\gamma^{\prime}$ and $\gamma^{\prime \prime}$ Phases in a Ni-base Superalloy;" ISIJ International, 36 (1996), 187-193.

58. J. F. Radavich; "The Physical Metallurgy of Cast and Wrought Alloy 718;" Superalloy 718 - Metallurgy and Applications; edited by E. A. Loria (Warrendale, PA: The Minerals, Metals and Materials Society, 1989), 